\title{
REGIONAL FEATURES OF RECREATIONAL NEEDS IN THE SYSTEM OF INDIVIDUAL HUMAN NEEDS
}

\author{
Alimova Guzal Alisherovna \\ Senior teacher at the Military-Technical Institute \\ of the National Guards of the Republic of Uzbekistan
}

guzal.guzal.1982@mail.ru

ORCID ID: orcid.org/0000-0002-0575-5678

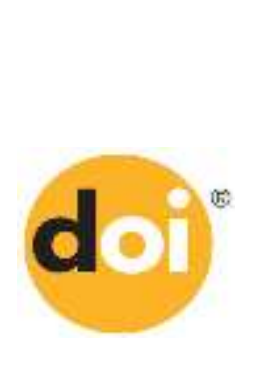

Crossref

Issue DOI http:/ / dx.doi.org/10.26739/2433-202x-2017-7-7

Article DOI http://dx.doi.org/10.26739/2433-202x-2017-7-7-5

\begin{abstract}
The article is devoted to regional peculiarities of recreational needs. Based on modern theories, the varieties of human needs are divided into three main groups: physical, social, intellectual. The classification of recreational needs, the hierarchy of the main groups of recreational motives is given. The analysis of the work of psychologists based on which the criteria for motivating recreational activities have been singled out is the choice of the goal, the time indicator, the implementation of the action. The social aspects of the formation of recreational needs are considered. The correlation of the tendency of growth of recreational needs and ecological situation in the world is revealed. For the full scale of the research conducted, the natural conditions of the regions of our country, industry and other factors affecting environmental conditions are analyzed. They, in turn, affect the health of the population. Because of the analysis, specific diseases characteristic of each region of Uzbekistan were identified, which in most cases form the need for a specific form of recreational resources. Based on the results of the study, the relevant conclusions were drawn.
\end{abstract}


Keywords: choice of goal, time indicator, implementation of actions, physical needs of a person, social needs of a person, intellectual needs of a person, types of diseases, environmental conditions, ecological situation.

The radical changes that took place in Uzbekistan in the 1990s lead to reformation not only in the public and individual needs of people, but also in recreation. In the process of the historical development of man, certain human needs have formed that allow him biological and social existence. But, according to experts, the process of forming needs is eternal, and some are replaced by others. Satisfaction of the old and the emergence of new social relations lead to the progress of society.

The further division of labor leads to changes in the forms of satisfying the needs of the individual, which depends on his place in the social stratum.

Depending on the income and social status of a person and the state of health, his needs are formed. At present, many researchers and specialists are engaged in studying the dynamics of needs (including recreational ones), which makes it possible to create prognostic models in recreation.

According to modern theories, the diversity of human needs is divided into three main groups:

- Physical;

-Social;

-Intellectual.

The physical needs of a person are those that determine its existence. Social and intellectual needs contribute to his spiritual, moral and mental development and determine his place in life.

For the successful development of the regional recreational and tourist industry, it is necessary to clarify the place of recreational human needs in the structure of the diversity of all its needs.

Among the many theories on this subject the Bestuzhev-Lada theory is considered to be the most acceptable. The scientist considers all human needs as "a unified system, all elements of which are in the relationship of interrelation and mutual influence"1. A person's life includes both his interests, and incentives, and aspirations.

A person existing in a specific society needs specific to this environment, its socio-psychological status. The place of human needs is determined by its social orientation. Despite the fact that each person, according to his life experience, position in society has individuality, the structure of his needs is

1Problems of the formation of sociogenic needs - Tbilisi: Metzniero, $1974.307 \mathrm{p}$.

Social science and humanities

G.Alimova 
relatively stable. In connection with the continuous development of society, new human needs arise, and this leads to a change in the hierarchy of his needs.

Primary, physiological needs appear from birth and exist throughout his life, so they must be met first. Then the secondary - intellectual and social will be satisfied. In connection with the development of society, the need for self-actualization begins to come to the fore. The main way to meet the needs is a person's labor activity, which, under the conditions of transition to market relations, becomes more and more diverse. In this regard, there is a significant change in the sphere of recreation. In the opinion of A.G. Zdravomyslov, "the study of the needs and interests of social groups reveals the hierarchy of the discovery of social patterns, which is the main goal of

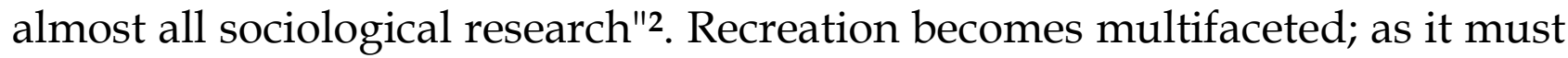
satisfy all the needs of a person, provide him full comfort (see Fig. 1).

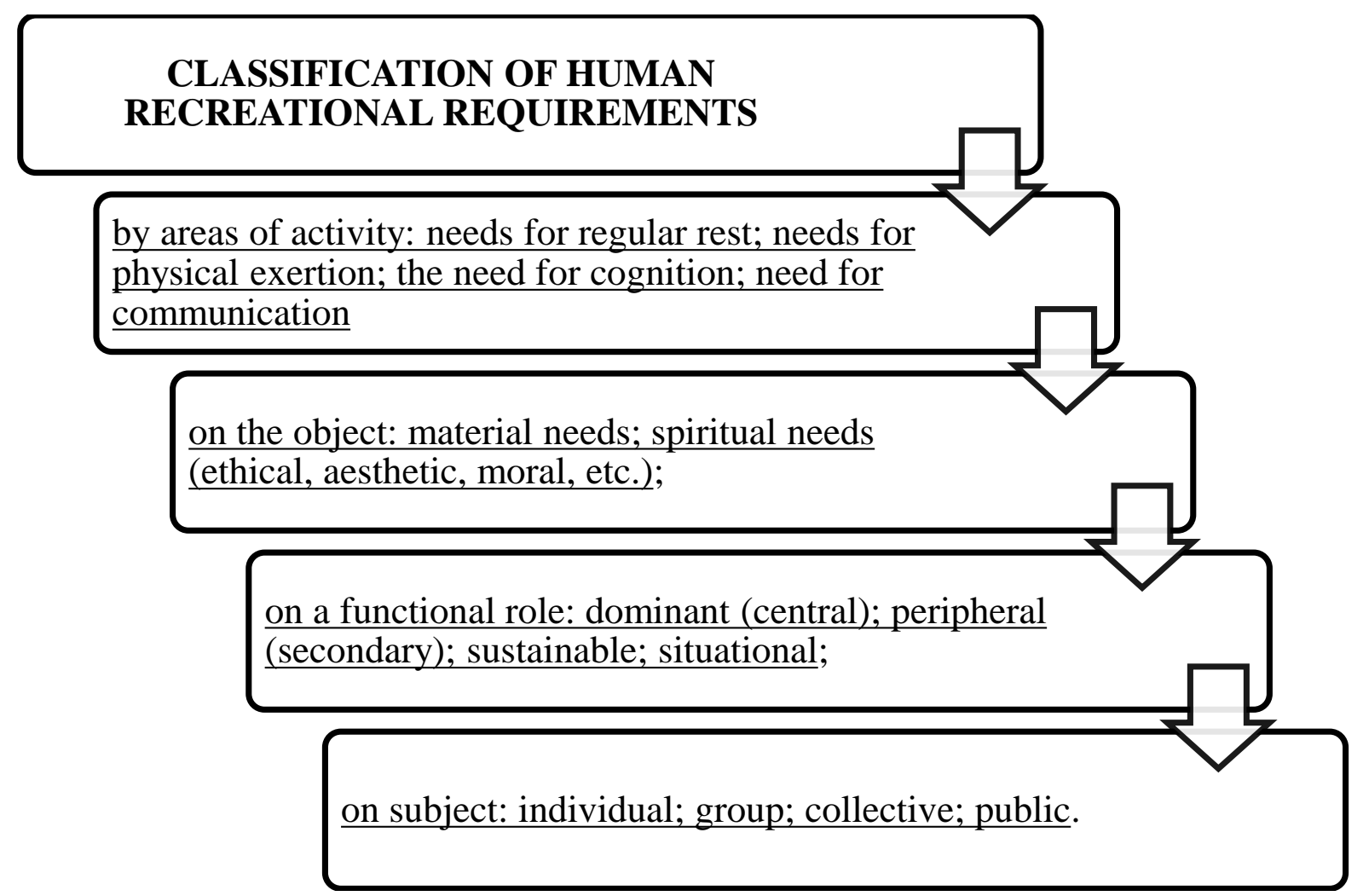

Fig. 1. Classification of recreational human needs.

The diversity of the individual's needs, his motives, desires leads to a

2Zdravomyslov A.G. Theoretical and methodological problems of research of social interests. Author's abstract. Dis. Doct. philos. sciences. - M., 1969. - 48 p.

Social science and humanities

G.Alimova 
variety of recreational activities of a person. Many scientists, geographers, sociologists, psychologists, etc., are engaged in this problem.

According to psychological research, there are three main criteria for motivating recreational activities:

- target selection;

- Time indicator;

- The realization of the action.

The first one is related to the goal that the recreant has set, and what he expects to receive from it. The second determines the activity of a person in his spare time. The third explains his actions in this situation.

Recreational activities depend on the physical condition of a person's lifestyle. In this regard, many scientists carry out research in the field of recreation at various stages of social development. Their conclusions boil down to the fact that in the conditions of the division of labor, both individual and collective human needs are formed (see Fig. 2.).

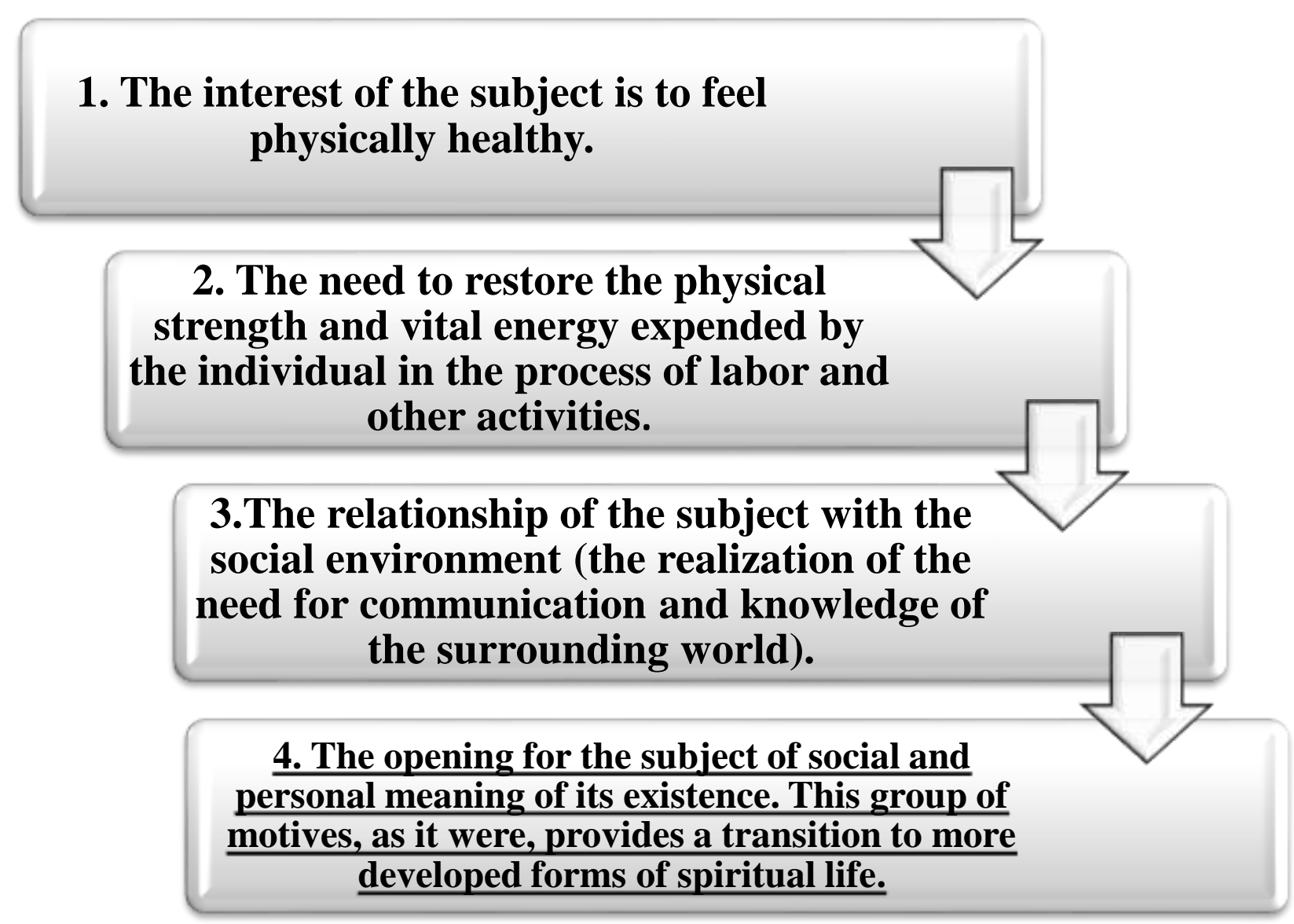

Fig. 2.Hierarchy of the main groups of recreational motives. 
This scheme is ideal, in it in the foreground, there are primary, partially satisfied motives of recreation, and then there are secondary needs. There are no in the life of the same indistinct differences. The hierarchy of needs reflects the social side of people. The hierarchy of needs reflects the social side of people's lives, as a person is constantly connected with the social environment in which he must engage in full-fledged work. For this, he needs the restoration of physical strength, vitality and spiritual well-being.

I.V. Bestuzhev-Lada notes that "each of the needs requires the satisfaction of a number of attendants, forming some complexes: production, material-consumer, spiritual-consumer, creative, etc."3.

As necessary, each of the needs can become the main, the rest will be secondary. With the satisfaction of some needs, others come first. In addition, if natural processes have a side-view of saturation, then sociogenic processes are limitless.

Individual recreation means satisfying people's basic physical needs. If this does not happen, then he begins to look for the means and sources of their satisfaction. This can be achieved through individual recreational activities, which generates a search for recreational migration flows.

Considering the issue in the regional aspect, one cannot help noticing that there are contradictions between recreational needs and the possibilities of recreational resources in a given territory.

To date, recreational needs are demonstrating rapid growth, not only in our country, but also throughout the world.

\section{So what is the reason for this growth?}

The main reason, in our opinion, is the sharp deterioration of environmental conditions, which in turn have a close connection with the activities of the people themselves (anthropogenic impact on the natural environment).

We will carry out a small regional analysis of the impact of natural and anthropogenic factors on the health of the population of our country.

The territory of Uzbekistan among the countries of Central Asia is distinguished by the peculiarity of internal natural socio-economic conditions. The structure of any region includes the natural and ecological situation, the quality of drinking water, population density, the specialization of industries, the industry of the region, etc. ${ }^{4}$.

3Problems of the formation of sociogenic needs - Tbilisi: Metzniero, 1974. 307 p.

${ }_{4}^{4}$ AmirchanovM.M.Theproblemsandprospectsofdevelopment of regions with recreational oriented economic:Dis. Doct. econ.sciences.Moskva. 1998.-391 p. 
For example, the Tashkent region, which has an industrial agrarian economy. So industrial areas of Angren-Almalyk are rich in deposits of mineral and raw materials. At the same time, industry in this region negatively affects its ecological situation. The resettlement of the population also has a relationship with the location of the productive forces in the region. The list of the most common diseases here has an "urban" nature, for example: diseases of the cardiovascular system, neurological, congenital anomalies and dangerous tumors. The greatest concentration of these diseases is observed in the cities: Tashkent, Angren, Almalyk, Bekabad and Chirchik.

The easternmost region of Uzbekistan is the Fergana Valley, which has an exceptionally peculiar geographical position. The region is bordered by high mountains, under the influence of which the climate is more stable. The summer season here is hot and long, and winters relatively warm and soft in other regions. However, it is the specificity of natural conditions that is the main cause of the spread of diseases. Thus, the winds of Kokand and Bekabad that are running here become the main reason for the spread of pneumonia and acute respiratory-respiratory diseases in the west of the region, especially in children and some infectious diseases (Vakhidova E.P., 2001). A slightly different situation in the Andijan region, where such diseases as dangerous tumors and skin diseases prevail. This is due to the fact that the Andijan region has a fairly high industrial development, which affects the ecological situation in the region.

The Mirzachul region also has its own specific set of diseases, which is associated with the steppe character of the territory. In the flat part of the region, due to the dryness of the climate $(200-350 \mathrm{~mm})$ and strong wind, diseases such as high blood pressure, diseases of the cardiovascular system and respiratory tract are common.

The Zarafshan region, which includes Samarkand, Bukhara and Navoi, is diverse both in terms of terrain, population and industry. It is rich in natural resources, as a result, they are actively developed, which in turn negatively affects the ecological situation and the health of the population.

In Urgut, Koshrabat and Payarik districts, diseases such as: blood, respiratory tract diseases, and in Kattakurgan, Ishtikhan and Pakhtachituberculosis are common. Also in the region are widespread diseases of the musculoskeletal system, diabetes mellitus and endocrine system disorders (Kamilova N.K., 2016). 
The Bukhara region also has its own natural and climatic features. Therefore, with "negative interaction" of the relief, climate, industry and infrastructure, the number of diseases increases. For example, in the region in the summer with a duration of 10-15 days there are perfectly windless days, when pollutants formed because of the activity of industrial enterprises and infrastructure remain for a long time, thus negatively affecting the health of the population.

However, in the Bukhara region, besides all sorts of environmental problems, there are excellent recreational resources, which are aimed at fully satisfying these needs. For example, the underground waters of the region are rich in low-mineralized water, and up to the waters rich in biologically active substances (iodine, bromine, boron, fluorine, iron, etc.).

So, in the hospital "Sitorai-Mokhi-Khosa", located four kilometers from Bukhara, actively use natural resources in the treatment of diseases such as diseases of the musculoskeletal, nervous and cardiovascular system. In addition, the following health facilities are active here: KhuzhaUbbon, KhuzhaZafaron and Zamonbobo, which specialize in the treatment of skin diseases.

The Lower Amu Darya region - here the ecological situation is quite difficult compared to other regions. This is connected with the Aral tragedy, which resulted in a sharp increase in infectious and epidemiological diseases, congenital anomalies and dementia in infants due to iodine deficiency, mother's anemia, water quality and climate. Especially the spread of these diseases is observed in Karauzak, Chimbay, Muynak and Kegeyli districts. Negative influence of the Aral problem is felt in the Khorezm region, where diseases such as blood diseases, hemopoietic organs and certain disorders involving the immune mechanism are widespread (4542, 1 people in 2015). And also because of the proximity of the location of groundwater to the surface of the earth (the ability of the soil to filter and purify water is reduced), the quality of drinking water is rather low, a high content of heavy metals and other negative substances is noted. As a result, diseases of the digestive system became widespread (8,966.1 people in 2015), in the republic for these diseases the Khorezm region is second only to Tashkent (17780.2 people in 2015) $)^{5}$.

The southern region, which includes Kashkadarya and Surkhandarya regions, where the environmental situation is characterized as unsatisfactory.

${ }^{5}$ State Statistics Committee of Uzbekistan. Statistical yearbook of the regions of Uzbekistan, Tashkent 2016, 244 p.

Social science and humanities

G.Alimova 
Many scientists are reduced to a common opinion, according to which the main reason for this state of affairs is the impact of an aluminum plant located on the territory of Tajikistan. The situation is aggravated by the direction of the wind (rose winds), which most of the pollutants (fluorinecontaining substances) transfers to the territory of the Surkhandarya region. As a result, not only landscapes change here, animal species disappear, but diseases such as skin and subcutaneous phlebitis diseases (1305.8 people in 2015), complication of pregnancy, childbirth and the postpartum period, congenital anomalies, deformations and chromosomal abnormalities and etc.

Based on the above analysis, the following conclusions are drawn:

1. The 1990s became a turning point in the social and economic life of our country, which led to changes in the structure of the public and individual needs of people.

2. Human needs are formed depending on the state of health, income and social status of a person.

3. The diversity of the needs of the individual, his motives, desires leads to a variety of recreational activities rights.

4. Needs are in constant movement, that is, satisfying some needs that were of paramount importance at a certain moment, conditions are created for the promotion of other needs.

5. The state of human health depends on both socio-economic factors and natural (deterministic approach). 


\section{References}

1. The Decree of the President of the Republic of Uzbekistan "On priority measures to ensure accelerated socio-economic development of regions" 08.08.2017, N PD-3182.

2. Avtsyn A.P. Introduction to geographical pathology. -M.: Medicine, 1972. - 328 p.

3. State Statistics Committee of Uzbekistan. Statistical yearbook of the regions of Uzbekistan, -Tashkent 2016, 244 p.

4. Zdravomyslov A.G. Theoretical and methodological problems of research of social interests. Author's abstract. Dis. Doct. Philos. sciences. - M., 1969. - 48 p.

5. Kamilova N.K. The doctrinal and practical issues of medicine geography.-T.: Shark, 2016. 264 p.

6. Problems of the formation of sociogenic needs - Tbilisi: Metzniero, 1974. 307 p. 